\begin{tabular}{lcl}
\hline PKS & REVISTA DE GEOGRAFIA & OJS \\
\hline $\begin{array}{l}\text { PUBLIC } \\
\text { KNOWLEDGE }\end{array}$ & (RECIFE) & OPEN \\
PROJECT & http://www.revista.ufpe.br/revistageografia & JOURNAL \\
\hline
\end{tabular}

\title{
A ÁGUA SOB A ÓTICA DA DIMENSÃO JURÍDICO- INSTITUCIONAL: CONSIDERAÇÕES INICIAIS
}

\author{
José Anderson de Sousa ${ }^{1}$ \\ ${ }^{I}$ Mestrando em Geografia pelo Programa de Pós-Graduação em Geografia da Universidade \\ Federal de Pernambuco. E-mail: jose-anderson-sousa@hotmail.com
}

Artigo recebido em 31/05/2018 e aceito em 25/08/2018

\begin{abstract}
RESUMO
O presente trabalho pretende discutir e verificar a relação entre as leis instituídas e ações das instituições do Estado brasileiro ligadas ao gerenciamento da água e a sua real efetivação na melhoria do acesso e da qualidade de vida das populações. Para tanto, faremos um levantamento do aparato da evolução jurídico e institucional no que concerne aos bens da natureza o seu estágio atual de recursos hídricos, confrontando as diretrizes e seus objetivos com os resultados e as interferências percebidas no território.
\end{abstract}

Palavras-chave: Acesso à água; direito territorial; Estado brasileiro.

\section{WATER UNDER THE OPTICAL OF THE LEGAL- INSTITUTIONAL DIMENSION: INITIAL CONSIDERATIONS}

\begin{abstract}
The present paper intends to discuss and verify the relation between the instituted laws and actions of the institutions of the Brazilian State related to water management and its real effectiveness in improving the access and the quality of life of the populations. To do so, we will make a survey of the apparatus of juridical and institutional evolution as regards the assets of nature its current stage of water resources, confronting the guidelines and their objectives with the results and the interferences perceived in the territory.

Keywords: Access to water; territorial law; Brazilianstate.
\end{abstract}




\section{INTRODUÇÃO}

São notórios os esforços desempenhados pelo Estado na criação da materialidade e de normas necessárias para dotar o território adequado à expansão do capital no campo. São políticas intensivas na estruturação do espaço pela criação de infraestruturas, normas e instituições diversas. Rico em bens naturais, no Brasil tem sido crescente a produção de commodities e do agronegócio em geral como planos de políticas que almejam a internacionalização da economia e uma maior margem de lucro, bem como pela competitividade no mercado.

Com destaque a essas políticas, as grandes obras de infraestruturas hídricas vêm sendo implantadas em várias partes do território, sempre travestidas pelo discurso de criação de uma segurança hídrica, de um gerenciamento eficiente e racional dos recursos hídricos e de proporcionar o acesso à água potável desde as cidades até às populações difusas.

Nesse contexto o presente trabalho pretende discutir e verificar a relação entre as leis instituídas e as ações das instituições do Estado ligadas ao gerenciamento da água e a sua real efetivação na melhoria do acesso e da qualidade de vida das populações. Para tanto, faremos um levantamento do aparato da evolução jurídico e institucional no que concerne aos recursos hídricos e seu estágio atual, confrontando as diretrizes e seus objetivos com os resultados e as interferências percebidos no território.

Como literaturas norteadoras centrais utilizaremos Pilar Carolina Villar e Wagner Costa Ribeiro, “A percepção do direito humano à água na ordem internacional”; “Quem cuida da água? Governança da água doce: a moldura jurídicoinstitucional nacional", organizado por Marussia Whately; "El hombre de hierro: Límitessociales y naturalesdel capital enla perspectiva de la Gran Crisis" de Armando Bartra; e "O direito humano a água e ao esgotamento sanitário como instrumento para promoção da saúde de populações vulneráveis”, de Priscila Neves-Silva e Léo Heller.

Além desses autores, a consulta a documentos de natureza jurídico e institucionais oficiais serão de grande valia como opção metodológica de estruturação do arcabouço dessa pesquisa e bem como através de obras que analisam a eficácia e o alcance dos objetivos das políticas públicas de recursos hídricos implantadas no território.

Na primeira seção “Água: de bem comum a recurso hídrico passível de privatização", desenvolve-se uma reflexão sobre a água e sua representação utilitária e 
simbólica como um bem essencial e indispensável para a subsistência das populações, ratificando e resgatando elementos pretéritos que demonstram o caráter essencial da água na produção do espaço e na reprodução das sociedades.

Coloca-se que a necessidade de acesso à água como um bem comum indispensável, naturalmente criou a necessidade de aperfeiçoar e de inventar objetos e técnicas novas que em sua funcionalidade possibilitasse um maior controle no armazenamento e utilização deste bem.

Levando à frente essa discussão afirma-se que as solidariedades e formas de encarrar esse bem foram se pervertendo para outra racionalidade. Nessa os fins econômicos dominam as relações de apropriação, tornando a água um recurso dotado de valor econômico e passível de comercialização. A água passa a ser privatizada e mediada como uma mercadoria. A essa transformação, acreditamos ser o Estado juntamente com a propriedade privada dois fatores responsáveis, desempenhando assim, papel importante.

Já na seção "O jurídico-institucional para além dos discursos: o cotejo com o Brasil real”, o enfoque se estabelece sobre um ramo específico que caracteriza esse processo contraditório, a saber: as mudanças no âmbito legislativo, às conferências realizadas, a criação de diversas instituições e suas ações por meio das políticas públicas.

Denominamos o processo mencionado como contraditório porque os discursos propalados apresentam às conferências, as leis, as políticas e as instituições como um avanço na garantia da segurança hídrica e na integração das bacias hidrográficas. Contudo, se percebe uma fragilidade dessas ações no sentido de diminuir a carência ou a falta de água, constantemente enfrentada pelas populações, seja pela restrição ao acesso ou pela qualidade desse bem.

ÁGUA: De bem comum a recurso hídrico passível de privatização

A percepção da importância da água para a manutenção da vida em geral e, em específico, como um bem essencial e indispensável para a subsistência das populações não são recentes, em documentos antigos a água já era citada como um elemento importante para as populações. "O ato de oferecer água era considerado por muitas culturas um dever, prescrito inclusive na Bíblia e no Alcorão” (VILLAR E RIBEIRO, p. 
359, 2012). Outro fato importante é quando da fixação de moradia, pois as comunidades privilegiavam locais próximos às fontes de águas.

No Ceará, local em que estreitamos nossas preocupações teóricas e práticas, os territórios do sertão, onde viviam tribos indígenas, foram expropriados destes de forma relativamente rápida, principalmente nos locais próximos aos rios onde melhor se encontrava água. Segundo Airton de Farias (2009, p. 23), "após os 30 primeiros anos do século XVIII, já eram amplas as áreas apropriadas pelos colonos", e "os rios, além de servirem de 'caminhos naturais' dos colonos na penetração dos sertões, possibilitaram ainda a pesca e a caça de animais que ali matavam a sede" (FARIAS, 2009, p. 22).

Neste sentido, nossas reflexões teóricas, mesmo se iniciando desde o Ceará, são concebidas a partir da abstração espacial do Cariri cearense, aportando assim para pensar o cenário das políticas públicas e normatização do território pelo viés dos recursos hídricos.

Figura 1 - Localização do Cariri Cearense e seus projetos hídricos de transposição de águas

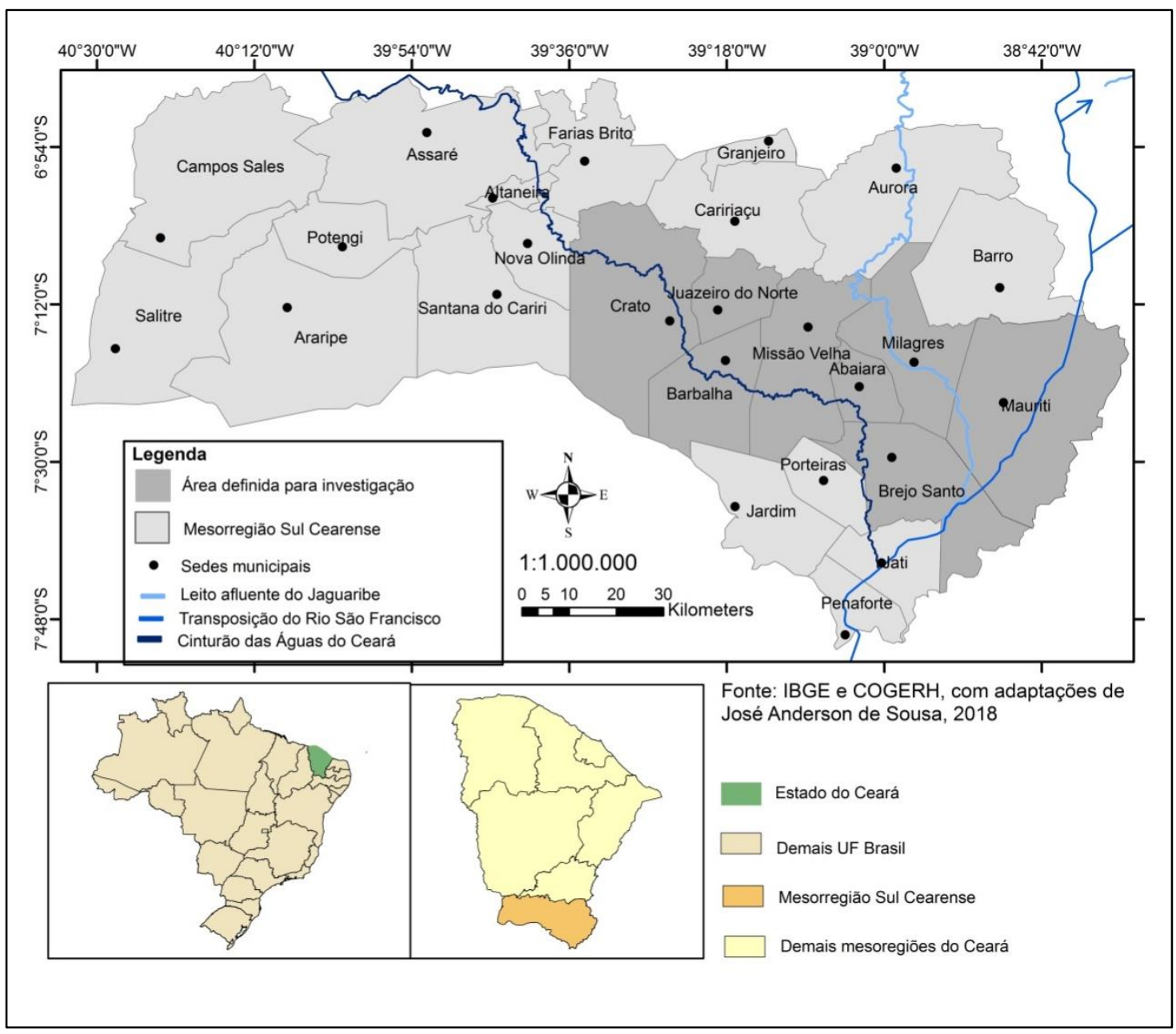


As preocupações com o acesso à água se davam, inicialmente, a exemplo de comunidades indígenas, pelo seu entendimento como um bem de uso e acesso comum. Diferente do entendimento atual, pelo poder público e de empresas, que a concebem como um recurso dotado de valor econômico que pode ser apropriado para fins privativos. Entendemos então que se faz necessário primeiro compreender essa diferenciação a fim de questionar as ideologias involucradas nas políticas públicas de recursos hídricos.

\begin{abstract}
El discurso de los commons, a fin de cuentas, es un discurso acerca de una mejor calidad de vida. Una vida empotrada en relaciones sociales, donde puede existir la pobreza material pero no la miseria, donde puede haber conflictos, pero no mecanismos de solución impuestos desde arriba, donde puede haber exclusión de acceso a determinados bienes y recursos (precisamente por proteger los recursos o por respetar los derechos de quienes, históricamente, se han hecho cargo de ellos) pero siempre se garantiza el acceso a los recursos indispensables para la sobre vivencia. (HELFRICH, 2008, p. 23).
\end{abstract}

A concepção de uso comum tem princípios e valores que foram sendo subvertidos e, em parte se explicam pela constituição do Estado, da propriedade privada e da apropriação desses bens para fins de mercado.

Concordamos com Feliciano (2015, p. 138) "que a existência desse aparelhamento do Estado, tanto pela via ideológica como pela repressiva e suas variações, foram mecanismos de manutenção de uma determinada ordem de poder, que necessita realizar sua reprodução".

O Estado, longe de ser apenas um mediador de conflitos entre classes, ele é fruto do sistema de exploração e subjugação de uma classe sobre outra. Juntamente com a propriedade privada, seu aparato discursivo e jurídico institucional é criado para garantir os interesses e a hegemonia de uma elite dominante.

Por esse viés, o entendimento das disparidades entre o que prevê a constituição, os documentos jurídicos oficiais, os planos das políticas públicas com as experiências empíricas concretas já consolidadas como realidade, se mostram elementares.

Mesmo em relação aos termos jurídicos demorou-se muito a debater sobre a formalização do direito humano à água. Villar e Ribeiro (2012) salientam que a intensificação do debate e formalização do direito humano à água só se estabelecerá a partir da década de 1970. 
Não obstante, desde os povos do mediterrâneo a localização das comunidades próximas a fontes de água eram importantes, sobretudo em locais em que as precipitações se davam de forma irregulares e as condições climáticas não propiciavam as condições para o desenvolvimento de uma agricultura satisfatória.

O Nordeste do Brasil se torna emblemático quando confrontado suas características climáticas e geológicas com o aumento crescente da demanda pelos usos das águas. Caracterizado com precipitações que variam em torno de $700 \mathrm{~mm}$ por ano, mal distribuídos no tempo e no espaço e com geologia predominantemente cristalina. $\mathrm{O}$ uso e criação de técnicas de armazenamento desse bem tem sido uma preocupação constante das populações e dos governos. Dessa forma, o presente estudo não tem como intenção questionar a falta de políticas e de ações do Estado em relação à gestão desse recurso.

O Estado do Ceará, por exemplo, é considerado um modelo quando da implantação de uma política de gestão de recursos hídricos, e é um dos Estados do Brasil que mais tem construído aparatos técnicos de engenharia hidráulica em seu território, intensificando-se esse processo com a fundação do DNOCS em 1909.

Tal Estado se apresenta como um exemplo ímpar na construção de obras hidráulicas, desde perímetros irrigados, pequenos e grandes açudes até projetos de transposição de águas, e, não dissociados desses, por criar as bases de sustentação de uma agricultura moderna com uso intensivo de água em pleno Semiárido.

As políticas de combate à seca no Nordeste remontam à época do Império. Dom Pedro II determinou a construção de açudes, entre outras ações, para diminuir os efeitos da estiagem entre os anos 1877 e 1879. O primeiro órgão de combate à seca foi criado em 1909, chamava-se Inspetoria de Obras Contra as secas (IOCS). Em 1919 tornou-se a Inspetoria Federal de Obras Contra a Secas (IFCOS). Em 1945 ganhou novo nome: Departamento Nacional de Obras Contra a Secas (DNOCS).

Abordaremos mais a frente que o Estado tem criado um conjunto de instituições responsabilizadas pela missão de gerir racionalmente os recursos hídricos e garantir o que prevê a legislação. O fato é que desde os primeiros açudes construídos pelo Departamento Nacional de Obras Contra as Secas, privilegiaram os interesses de uma minoria e alimentaram o que foi denominado por Celso Furtado como "indústria da seca". Beneficiando coronéis, as obras do DNOCS serviam como compra de votos na medida em que os açudes eram construídos nas terras dos coronéis e, então, cabia a esses decidir quem poderia usufruir desses recursos. 
Criam-se condições excludentes de acesso aos recursos hídricos que não estão associados "[...] unicamente às características naturais climáticas, mas principalmente, às decisões geopolíticas associadas à manutenção da hegemonia latifundiária e do mercado da água”. (GONÇALVES e OLIVEIRA, 2009, p. 113-114).

Ressalta-se que, sobretudo em áreas com pouca disponibilidade de água, as comunidades foram criando e adaptando técnicas de hidrologia, armazenamento e construção de canais. A busca pelo aperfeiçoamento técnico é imanente à natureza humana. Historicamente o homem tem criado e desenvolvido novas técnicas de apropriação e domínio da natureza.

Entretanto, a intencionalidade e função do uso das técnicas que de início tinham como pressuposto inicial e eixo principal a melhoria da qualidade de vida do homem, através da relação dialética e solidária com a natureza e seus ciclos naturais, se perverte cada vez mais em função da expansão hegemônica do capital e sua busca pelo lucro, alicerçado em paradigmas técnicos destrutivos da natureza e de cada vez mais precarização na qualidade e reprodução dos sujeitos sociais.

Nas últimas décadas, com início em 1970, além da intensificação do debate e a formalização do direito humano à água na comunidade internacional junto com o crescente aumento da demanda por usos das águas, o Estado brasileiro começa a incorporar na legislação e a partir da criação de secretarias e instituições, diversas diretrizes em que o intuito oficial se fixa na tarefa substancial de garantir o acesso à água sem discriminação e de forma equitativa em todo o território.

O JURÍDICO-INSTITUCIONAL PARA ALÉM DOS DISCURSOS: O cotejo com o Brasil real

A percepção do direito humano a água na ordem internacional só será declarada de forma independente de outros direitos em 2002 pelo Comitê dos Direitos Econômicos, Sociais e Culturais das Nações Unidas na sua Observação Geral n. 15. Até esta ocasião, o direito a água é inferido da Declaração Universal de Direitos Humanos, instituída em 1948, de forma indireta. Esse fato se repetirá em outras declarações e conferências internacionais realizadas que concebiam o direito a água apenas como relacionado e derivado do direito a vida e a saúde (VILLAR E RIBEIRO, 2012).

Entre estas estão a Declaração de Estocolmo, de 1972, a Conferência das Nações Unidas sobre Água, em 1977, a Conferência Global sobre Água Potável e 
Saneamento, em 1990, a Conferência Internacional sobre Água e o Meio Ambiente, em 1992, a Conferência das Nações Unidas sobre Meio Ambiente e Desenvolvimento, Rio 92 em 1992, a Conferência Internacional sobre Água e desenvolvimento sustentável, em 1998, e a Conferência Internacional sobre a Água Doce, em 2001(VILLAR E RIBEIRO, 2012).

Dada a quantidade de Conferências realizadas e os debates sobre águas resultantes destas, mesmo antes do direito humano à água tornar-se explícito, não há dúvidas de que houve avanços expressivos no âmbito internacional. Dessa forma a água é entendida como um direito fundamental que deve ser garantida pelos Estados.

$\mathrm{Na}$ tentativa de consorciar com as prerrogativas internacionais, a Constituição Federal de 1988, no Brasil, prevê que cabe à União, Estados e Municípios competências materiais e legislativas na questão da água, entendo-a como um elemento constituinte indissociável nos serviços de saneamento básico, ao meio ambiente, à saúde e qualidade de vida. Assim como no âmbito internacional, o problema da água passa a ser tratado veementemente como um pré-requisito básico para a garantia de outros direitos previstos na Constituição Federal, e esta última servirá de suporte para o planejamento e criação de instituições incumbidas da tarefa de garantir o gerenciamento equitativo e horizontal dos recursos hídricos (WHATELY, 2016).

O ano de 1997 foi um marco na formalização das competências e objetivos para a gestão dos recursos hídricos no Brasil, quando foi promulgada a Lei das Águas (Lei n. 9433/1997), a Política Nacional de Recursos Hídricos (PNRH) e o Sistema Nacional de Gestão de Recursos Hídricos (SINGREH) (Idem, 2016). Como parte desse aparato jurídico e institucional foram criadas e incluídas ainda o Conselho Nacional de Recursos Hídricos (CNRH), os Comitês de Bacia Hidrográfica (CBHs), as secretarias de recursos hídricos dos Estados, O Ministério do Meio Ambiente (MMA) e ainda a Agência Nacional de Água (ANA). Mesmo com competências e objetivos específicos distintos, no plano teórico, todas devem convergir esforços, também práticos, para a criação de melhorias na distribuição, qualidade, oferta, regulação e cobranças pelos usos das águas.

A água deve ser assegurada com padrão adequado de potabilidade para às atuais e para as gerações futuras, sem discriminação e de forma equitativa independentemente da situação financeira ou de localização espacial.

Ressalte-se que muitas ações e políticas públicas com o foco na gestão das águas foram executadas bem antes da criação desse aparato institucional, a exemplo da 
atuação do que hoje é o Departamento Nacional de Obras Contra as Secas. Esse Departamento, criado ainda em 1909 com o título de Inspetoria de Obras Contra as Secas - IOCS atuou principalmente na criação de sistemas técnicos de engenharia. Construiu açudes, estradas, pontes, portos, ferrovias, hospitais, campos de pousos e etc.,

Na prática, mesmo após 1997, tem ocorrido uma continuidade e expansão de obras de engenharia, sob o subterfúgio da busca pelo desenvolvimento, até mesmo em outras esferas do domínio público. Em termos práticos o Estado tem entendido a questão hídrica como um problema técnico de engenharia hidráulica sem considerar as demandas sociais e históricas dos sujeitos e suas especificidades.

Todos esses órgãos procuram definir metas e solucionar os problemas com obras para armazenar água e suprir a população, a agricultura e a pecuária. Mas tem sido insuficiente. Além do desmatamento, a seca do Nordeste está ligada à falta de políticas que realmente funcionem em benefício da população.

Devido a interesses e pressões de mercado representados, em grande parte por empresários e empresas do ramo da apropriação e comercialização da água, as obras de engenharia hidráulica, ao invés de garantir a todos o uso da água como um bem comum e que conflua com práticas sociais de relações solidárias com o meio ambiente, tem se omitido quando da crítica do modelo de uso, apropriação e exploração dos bens naturais alicerçados em paradigmas destrutivos dos bens naturais e de transformação das comunidades e populações em objetos de exploração e enquadramento pelo capital.

Em síntese, os avanços constatados quando da discussão do acesso à água como um direito a ser assegurado para todos é entendida como uma concessão, porém, apenas no plano teórico, já que o funcionamento das grandes obras hidráulicas demonstra uma realidade controversa e diferente dos planos propalados. Estes últimos são bastante difundidos quando da necessidade de criar um ambiente de aceitação pela população para a construção dessas infraestruturas.

Dessa forma, fica claro o caráter ideológico e a dupla face das interferências do Estado no gerenciamento dos recursos hídricos. Para Haesbaert e Porto-Gonçalves (2006, p. 39) “a interferência periódica do Estado é sempre uma 'faca de dois gumes' na consolidação da globalização capitalista, pela contradição que lhe é inerente entre a defesa de interesses públicos e de interesses privados [...]”.

En resumen, las formas institucionalizadas de ciudadanía que predominan actualmente son parte integral de la democracia capitalista y se han desarrollado en íntima correspondencia con otros aspectos estructurales clave 


\begin{abstract}
del sistema capitalista. De este modo, el proceso de ciudadanización está estrechamente relacionado con el desarrollo de relaciones capitalistas construidas en torno al elemento central de la sociedad capitalista: la mercancía y el consecuente proceso de mercantilización que continúa su permanente expansión hacia nuevos territorios. Em conexión con esto, la mercantilización es un proceso de largo plazo por El cual las relaciones entre los seres humanos pasan a ser crecientemente mediatizadas y transformadas por la lógica de la producción y circulación de mercancías, un proceso centrado en la apropiación privada -no común- de la naturaleza (CASTRO, 2008, p.74).
\end{abstract}

Ademais, não apenas por parte dos atores privados, mais em consonância com os planos e estratégias desses, o aparato técnico-burocrático e institucional do Estado intervém no espaço de modo a exercer seu papel histórico, conformando e os tornando aptos para as investidas do capital hegemônico e cada vez mais monopolista.

Entende-se então que as grandes obras de infraestruturas hídricas e as práticas de gestão dos recursos hídricos não se dissociam dos planos de expansão do capital no campo, pelo contrário, os aparatos técnicos jurídicos e institucionais do Estado são frutos desse processo.

\title{
CONSIDERAÇÕES FINAIS
}

As declarações, conferências e reuniões sobre o direito humano a água, a incumbência do Estado como o responsável por garantir e instituir as condições para o acesso equitativo a água potável junto com a instituição de leis nacionais e a criação de instituições e secretarias com a missão de operacionalizar o acesso de água potável a todos, se reduzem a meras categorias formais, perdendo sua verdadeira significação na medida em que não tem atuado na aplicação dos princípios e objetivos que norteiam as leis, o Estado e suas políticas.

Em tempos hodiernos o acesso desigual desse bem torna a questão mais complexa, pois o modelo paradigmático de produção e sociabilidade construído durante os últimos quinhentos anos se exacerba cada vez mais no sentido de acumulação de capitais, de alienação de sujeitos e de transformação de todos os bens, materiais e imateriais em mercadorias. 


\section{REFERÊNCIAS}

BARTRA, Armando. EI hombre de hierro: Límitessociales y naturalesdel capital en la perspectiva de la Gran Crisis. Ed. 2 , Editorial Itaca, 2014.

CASTRO, José Esteban. Los bienes comunes y la ciudadanía: contradicciones de una relación en pleno desarrollo. In: HELFRICH, Silke (org). Genes, bytes y emisiones: bienes comunes y ciudadanía. Fundación Heinrich Böll: Ciudad de México, 2008.

FARIAS, Airton de. História do Ceará. 5ª ed. Fortaleza: Edições Livro técnico. 2009.

FELICIANO, Carlos Alberto. Estado, apropriação e concentração de terra e poder: da propriedade como direito natural ao questionamento da função social da terra. In: MITIDIERO JÚNIOR, Marco Antonio; GARCIA, Maria Franco; VIANA, Pedro Costa Guedes (Org.). A questão agrária no século XXI: escalas dinâmicas e conflitos territoriais. São Paulo: Outras Expressões, 2015.

GONÇALVES, Claudio Ubiratan; OLIVEIRA, Cristiane Fernandes de. Rio São Francisco: as águas correm para o mercado. Boletim Goiano de Geografia. v. 29, n. 2, 2009. p. 113-125.

HAESBAERT, Rogério; PORTO-GONÇALVES, Carlos Walter. A nova des-ordem mundial. 2. Reimp. São Paulo: UNESP, 2006.

HELFRICH, Silke (org). Genes, bytes y emisiones: bienes comunes y ciudadanía. Fundación Heinrich Böll: Ciudad de México, 2008.

NEVES-SILVA, Priscila; HELLER, Léo. O direito humano a água e ao esgotamento sanitário como instrumento para promoção da saúde de populações vulneráveis. Ciência \& Saúde Coletiva (Online), v. 21, p. 1861-1870, 2016.

VILLAR, Pilar Carolina; RIBEIRO, Wagner Costa. A percepção do direito humano à água na ordem internacional. Revista de Direitos Fundamentais \& Democracia (Unib Brasil), v. 11, p. 358-380, 2012.

WHATELY, Marussia. Quem cuida da água? Governança da água doce: a moldura jurídico-institucional nacional. 2016. 